\title{
ENERGY SAVINGS IN AUXILIARY VENTILATION SYSTEMS OF UNDERGROUND MINES
}

\author{
Alper Gonen $1 \square$ (iD) \\ ${ }^{1}$ Mining Engineering Department, Dokuz Eylul University, Turkey
}

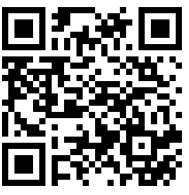

Received 21 September 2021

Accepted 12 October 2021

Published 31 October 2021

\section{CorrespondingAuthor}

Alper Gonen, alper.gonen@deu.edu.tr DOI 10.29121/ijetmr.v8.i10.2021.1055

Funding: This research received no specific grant from any funding agency in the public, commercial, or not-for-profit sectors.

Copyright: (C) 2021 The Author(s). This is an open access article distributed under the terms of the Creative Commons Attribution License, which permits unrestricted use, distribution, and reproduction in any medium, provided the original author and source are credited.

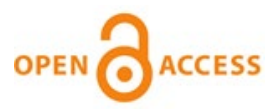

\section{ABSTRACT}

Energy is a basic need for industries around the world. In recent years, electrical power costs have risen considerably and this rise is likely to continue in the future. Meanwhile, the increasing cost of ventilating mines safely and efficiently is of vital importance. Ventilation on demand has the potential to optimize electrical consumption while maintaining the safety of mines. This paper investigates the energy efficiency enhancement through ventilation on demand in underground mines by installing variable speed drives on the auxiliary mine ventilation fans to provide variable airflow control. Variable speed drives are cost effective and manageable and require low maintenance. It has been estimated that a total electrical energy saving of $324,300 \mathrm{~kW}$, or $53 \%$, can be achieved in 1 year by using variable speed drives. Therefore, it is possible to reduce CO2 emissions by 155.6 tons per year with a simple payback period of 5 months 220 days.

Keywords: Auxiliary; Energy Saving; Mining; Variable Speed Drive; Ventilation

\section{INTRODUTION}

Improving the effectiveness of industrial energy use is of worldwide significance. The industrial sector, including refining, mining, manufacturing, agriculture, and construction, accounts for the largest share of energy consumption of any end-use sector, with more than $50 \%$ of end-use energy consumption. World energy consumption is expected to rise to nearly $50 \%$ between 2018 and 2050, with the industrial sector being the largest consumer of energy. World industrial sector energy use is anticipated to increase by an average of 1\% per annum in the next 30 years (E.I.O. (2019)). However, electricity production has increased about four times in the last 40 years (Malli and Yetkin (2019)).

In many underground mines, the continuous operation of ventilation systems represents a significant percentage of the power used. The demand for ventilation has also increased because of the increased use of diesel equipment. Main fans, air chillers, and other elements of ventilation (Wallace et al. (2015)) can use up to $70 \%$ of the energy in a mine. The rising energy expenses connected with mining have become a problem that needs to be resolved for future sustainable production. 
The aim of ventilation on demand (VOD) systems is to optimize fresh air supply only where it is required and when needed. Variable speed drives (VSDs) are the key components of VOD and are regularly used in the heating, cooling, ventilation, and air conditioning of buildings to change pump and fan speeds. Speed control is used in these applications to regulate water or airflow because velocity adjustment is an energy-efficient flow control technique (Teitel et al. (2008)). VSDs are highly efficient, easy to control, and require little maintenance. They have now become the preferred choice of drives in many applications.

Speed control is the most energy-efficient flow control technique because it needs the least quantity of energy to fulfill the load. Technology advances make VSD applications more of a sector standard. Implementing VSDs in mine cooling systems has been reported to be economically feasible. It is possible to achieve complete annual power savings of $144,721 \mathrm{MWh}$ or $32.2 \%$ (Plessis et al. (2013)). The purpose of this research is to evaluate the use of VSDs for energy savings in a model study of a ventilation system of an underground mine using the cut-and-fill method to extract ore.

\section{MATERIALS AND METHODS}

\subsection{VSD}

Electric motors are typically intended to operate at constant speeds; that is, different motors are required to achieve different speeds. The engines are sized to provide the highest energy output needed in most applications. VSDs work by controlling the waveform of the current and voltage supplied to the motor (Tolvanen (2008)). They operate by regulating the present waveform and voltage delivered to the motor. VSDs are used in electromechanical drive systems to regulate $\mathrm{AC}$ engine velocity and torque by varying the input current and voltage frequencies (Dubey (2001)). In Figure 1, one of the many feasible circuits for regulating an induction engine's velocity is schematically depicted (Ozdemir (2004)). A VSD is linked between the electric motor and the power supply system. The main parts of the system are a multiphase diode rectifier, a control and safety regulator, and an inverter.

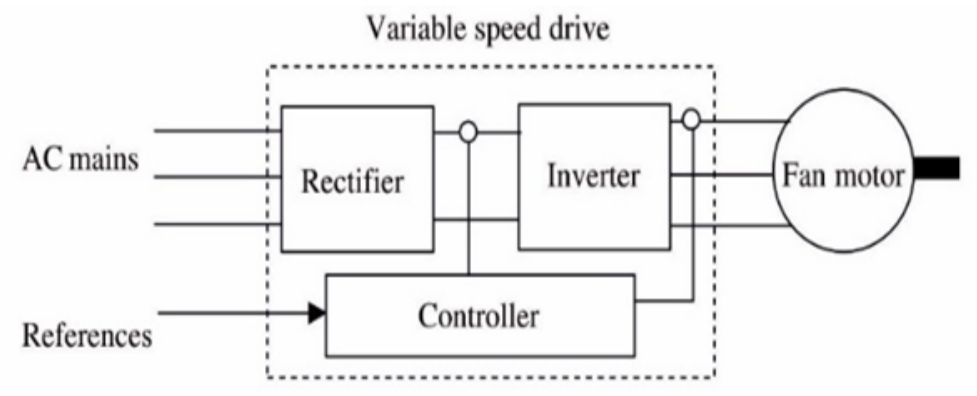

Figure 1 VSD system block diagram

Kaya and Kilic (2004), Khalid (2014), Mecrow and Jack 
(2008). VSD systems decrease energy consumption, increase energy effectiveness, improve the power factor and process accuracy, and decrease the mechanical pressure on the fan and motor.

In fan applications, energy consumption follows the laws of affinity. These regulations are used when changing variables to estimate a fan's working efficiency. Equations 1-3 represent the widely used fan laws, showing the connection between the fundamental parameters of fans (Simpson and Marchi (2013)).

$$
\begin{aligned}
& \frac{Q_{a}}{Q_{b}}=\frac{N_{a}}{N_{b}} \\
& \frac{P_{a}}{P_{b}}=\frac{\left(N_{a}\right)^{2}}{\left(N_{b}\right)^{2}} \\
& \frac{H P_{a}}{H P_{b}}=\frac{\left(N_{a}\right)^{3}}{\left(N_{b}\right)^{3}}
\end{aligned}
$$

Where $\mathrm{Q}$ is the flow, $\mathrm{N}$ is the speed, $\mathrm{P}$ is the pressure, and $\mathrm{HP}$ is the power.

The laws of affinity (also called cubic laws) state that the output or flow of a fan is directly proportional to its speed. The terms $\mathrm{Q}$ (flow) and $\mathrm{N}$ (speed) in the above expressions, under Equation 1, are interchangeable. So, $Q$ can be substituted in place of $\mathrm{N}$ in Equation 3.

$$
\frac{H P_{a}}{H P_{b}}=\frac{\left(Q_{a}\right)^{3}}{\left(Q_{b}\right)^{3}}
$$

Therefore, the required power becomes proportional to the cube of the flow. The fan would operate at $50 \%$ of the speed to generate $50 \%$ of the flow. At this stage of operation, the fan would only involve $12.5 \%$ of the rated power $(0.5 \times 0.5 \times 0.5=$ 0.125 or $12.5 \%$ ) (Lönnberg (2007)). In theory, a $50 \%$ decrease in flow results in an $87.5 \%$ decrease in the energy input. However, the exponent often ranges from two to three in real-world applications, which means that the savings are reduced despite the changes in the exponents. As shown in Figure 2, reducing the fan engine speed by $10 \%$ requires about $70 \%$ of the energy, whereas reducing the fan engine speed by $20 \%$ requires only $50 \%$ of the power. The installation of a VSD on the fan engine enables the fan to match this decreased ability automatically, slowing down as a reaction to decreased demand, and thus saving energy (Gonen (2018)). 


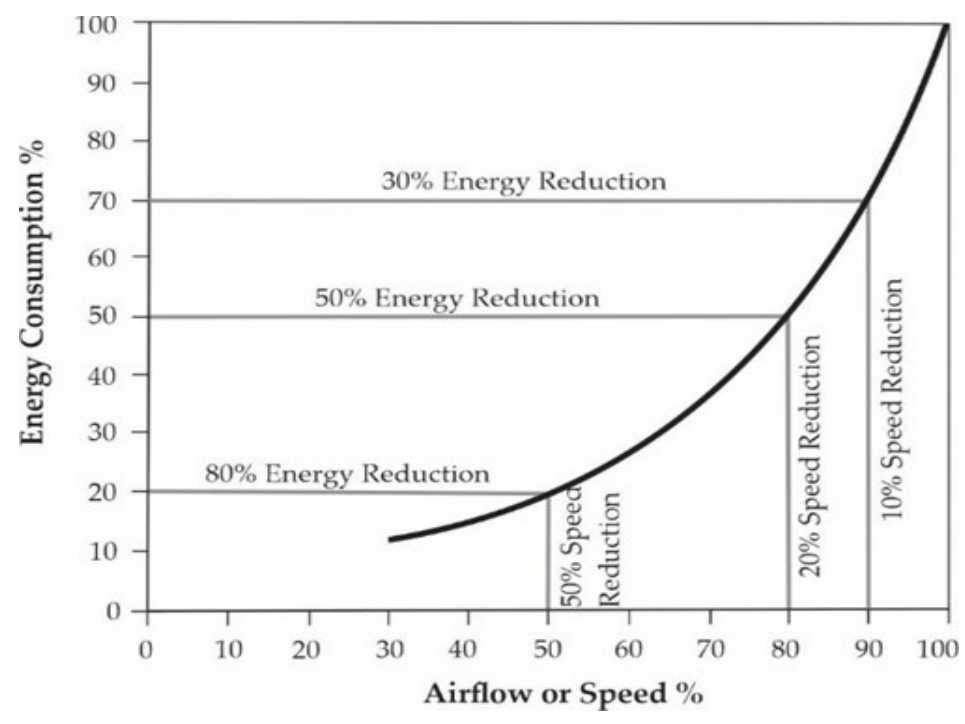

Figure 2 Energy consumption reduction with reduced motor speed

\subsection{UNDERGROUND MINE MODEL}

Ventilation can be defined as the lifeblood of a mine in which the intake airways act as arteries by bringing oxygen to the mine's working areas and act as veins by removing pollutants from the mining areas to be expelled into the atmosphere (McPherson (1993)). The primary objective of an underground ventilation system is to provide adequate amount and quality of fresh air to dilute contaminants to secure levels in all areas of the mine where the staff needs to work or travel.

A ventilation shaft or audit is developed to supply fresh air to the mine. At this point, regulators and continuously installed ventilation fans control the direction of airflows. For distributing fresh air to working areas, auxiliary ventilation systems are used with temporarily mounted ventilation fans and spiral ducting (Tuck (2011)). The underground mine ventilation supplies fresh and adequate volume of air to dilute and remove dust and noxious gases and controls the temperature of the working areas. The primary sources of these harmful gases are the equipment running on diesel engines and explosive blasts. In this study, an underground mine extracting ore by the cut-and-fill method is evaluated in terms of the ventilation requirements and the adaptation of the VSDs to the auxiliary ventilation system.

Stephan (2011)). In cut-and-fill mining, the ore is extracted in several horizontal drifting slices. In overhand cut-and-fill mining (mining on top of the backfill), which is the most preferred variation, mining starts at the lower level and works upward. When a slice is mined out, the gap is filled with waste material (Figure 3). To reach the ore body, generally, a spiral ramp is driven, and several stopes can be extracted simultaneously to provide flexibility in the mine. 


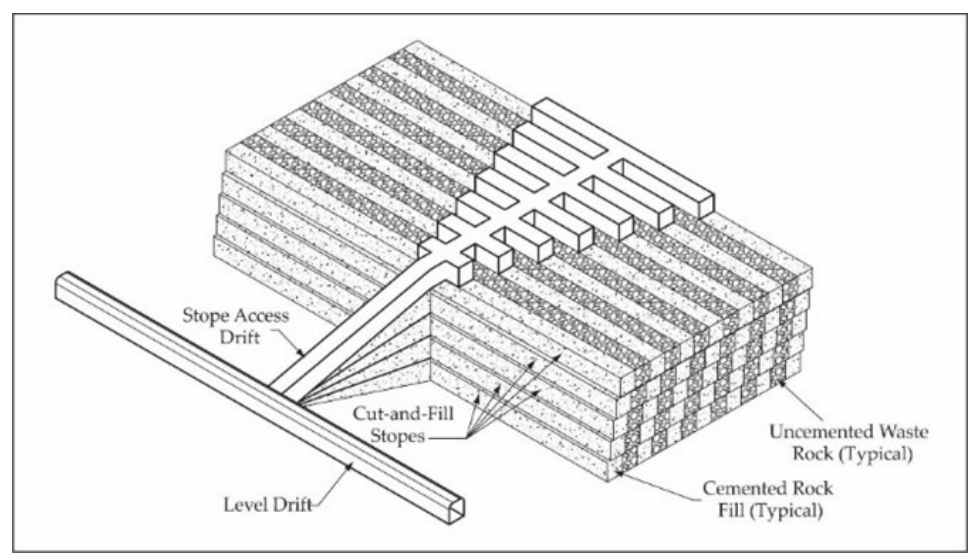

Figure 3 Typical overhand cut-and-fill mining method

\subsection{USING VSD WITH AUXILIARY VENTILATION FANS}

With their low capital cost and ease of use, mine fans are normally controlled with across-the-line starters. Ventilation fans are manually regulated in hard rock mining and operated at maximum capacity $24 \mathrm{~h}$ a day. Therefore, given that these fans operate at $100 \%$ rated speed, a large amount of current is drawn.

Auxiliary ventilation is the most utilized way to supply fresh air to blind working areas (Tuck (2011)). As there are many auxiliary fans in an underground mine, energy can be saved by managing the power supplied to these fans. A decrease in energy consumption is possible by controlling the ventilation system to supply air only where it is necessary. Therefore, VOD can be achieved for each mining stope depending on the activity in the area. For this purpose, wireless or wired mine tracking systems can transmit data via communication systems to a real-time ventilation monitoring system. Tags and readers are used to locate and determine the position of workers and vehicles. Tags are installed in mobile equipment and all cap lamps. The system can detect the presence of particular tags in an area and make ventilation adjustments accordingly. When tags leave an area, ventilation can be automatically adjusted again (Figure 4).

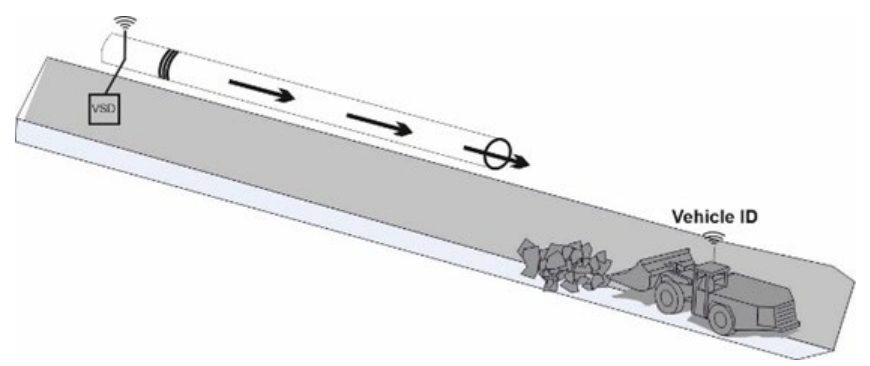

Figure 4 Equipment detection system

Diesel equipment is widely used in fully mechanized cut-and-fill mining. In general, the ventilation specifications are determined by the total power of the diesel machines for the entire mine, individual parts, or working areas. There is a wide variation between countries when it comes to calculating the standard ventilation requirements of the mines that use diesel engines. The fundamental principle is that adequate ventilation should be available to dilute the exhaust gases 
and particulates below their limit values. For design purposes, 0.06 to $0.08 \mathrm{~m} 3 / \mathrm{s}$ of airflow for each kilowatt of diesel power is accepted as a general rule. As seen in Table 1, ventilation regulations vary by country, but airflow of $0.06 \mathrm{~m} 3 / \mathrm{s}$ per $\mathrm{kW}$ seems to be the best practice most of the time (Halim (2017)).

\begin{tabular}{ll}
$\begin{array}{l}\text { Table } 1 \text { Restrictive legislation for diesel mining equipment in major mining } \\
\text { countries }\end{array}$ & Ventilation rates \\
\hline Location & $\begin{array}{l}\text { Varies by state and territory, from } 0.05 \text { to } 0.06 \mathrm{~m}^{3} / \mathrm{s} \mathrm{per} \mathrm{kW}, \\
\text { most commonly } 0.06 \mathrm{~m}^{3} / \mathrm{s} \text { per } \mathrm{kW}\end{array}$ \\
Australia & $\begin{array}{l}\text { Varies by province and territory, from } 0.047 \text { to } 0.092 \mathrm{~m}^{3} / \mathrm{s} \\
\text { per } \mathrm{kW} \\
\text { Canada }\end{array}$ \\
& $\begin{array}{l}\text { most commonly } 0.06 \mathrm{~m} 3 / \mathrm{s} \text { per } \mathrm{kW} \\
\text { South Africa }\end{array}$
\end{tabular}

In cut-and-fill mining, the ore is extracted from many production stopes simultaneously, and every stope needs to be ventilated by a permanently installed auxiliary fan. The auxiliary ventilation fan selected for this study is a unit with a $100 \%$ flow rating of $27 \mathrm{~m} 3 / \mathrm{s}$ and a motor shaft power requirement of $75 \mathrm{~kW}$.

Table 2 shows the possible energy savings from speed reduction through the use of VSDs on industrial motors (Saidur et al. (2010)). These data have been used to estimate the energy savings of the selected $75-\mathrm{kW}$ auxiliary ventilation fan motor using a VSD (Figure 5).

\begin{tabular}{|cc|}
\hline Table 2 Possible savings of VSD through speed reduction \\
\hline Average speed reduction (\%) & Potential energy savings (\%) \\
\hline 10 & 22 \\
20 & 44 \\
30 & 61 \\
40 & 73 \\
50 & 83 \\
60 & 89 \\
\hline
\end{tabular}

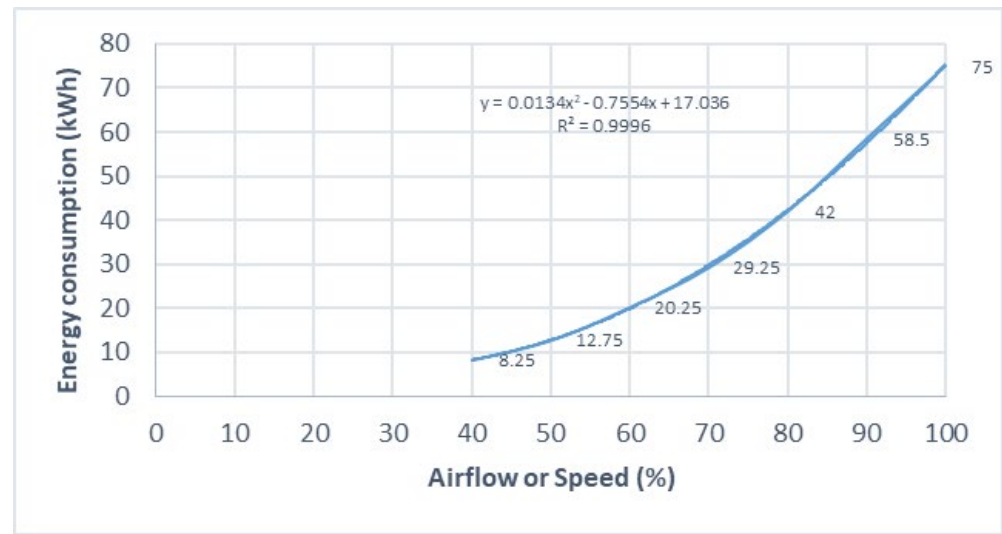

Figure 5 Speed reduction-energy consumption relationship with VSD 
Table 3 shows the diesel equipment used in a stope during the production cycle. The automated fan system responds to signals emitted from the RF tags, which are tracking devices installed on underground machinery and worn by all the underground employees.

As miners and vehicles pass into various areas of mine, the system, only if needed, activates the fans by adjusting the fan speed on the basis of the carbon emissions expected from the specific vehicle type.

\begin{tabular}{|cc|}
\hline Table 3 Diesel equipment fleet & \\
\hline Unit & $\begin{array}{c}\text { Diesel engine } \\
\text { power (kWh) }\end{array}$ \\
\hline Jumbo drill & 140 \\
\hline Loader & 170 \\
\hline Haulage truck & 220 \\
\hline Explosive charger & 125 \\
\hline Rock support drill rig & 60 \\
\hline
\end{tabular}

Table 4 shows the diesel engine power of vehicles entering a stope and the airflow requirement during each operation in the stope.

As mentioned previously, the airflow requirement for a particular vehicle is determined by multiplying the rated diesel engine power of the vehicle by the regulatory airflow requirement. In this model study, it was assumed that $0.06 \mathrm{~m} 3 / \mathrm{s}$ of air would be needed per kilowatt of diesel engine power, and the airflow requirement for all diesel-powered equipment has been calculated accordingly.

\begin{tabular}{|c|c|c|c|c|c|c|}
\hline \multirow[b]{2}{*}{ Operation } & \multicolumn{5}{|c|}{ Airflow requirement during each operation $\left(\mathrm{m}^{3} / \mathrm{s}\right)$} & \multirow[b]{2}{*}{$\begin{array}{l}\text { Total airflow } \\
\text { requirement } \\
\text { (m3/s) }\end{array}$} \\
\hline & $\begin{array}{l}\text { Jumbo } \\
\text { drill }\end{array}$ & Loader & $\begin{array}{l}\text { Haulage } \\
\text { truck }\end{array}$ & $\begin{array}{l}\text { Explosive } \\
\text { charger }\end{array}$ & $\begin{array}{c}\text { Rock } \\
\text { support } \\
\text { drill rig }\end{array}$ & \\
\hline Drilling & 8.40 & 10.20 & - & - & - & 18.60 \\
\hline $\begin{array}{l}\text { Explosive } \\
\text { charging }\end{array}$ & - & 10.20 & - & 7.50 & - & 17.70 \\
\hline $\begin{array}{l}\text { Blasting } \\
\text { reentry }\end{array}$ & - & - & - & - & - & 27.00 \\
\hline Mucking & - & 10.20 & 13.20 & - & - & 23.40 \\
\hline $\begin{array}{l}\text { Cleaning } \\
\text { and rock } \\
\text { support }\end{array}$ & - & 10.20 & - & - & 3.60 & 13.80 \\
\hline
\end{tabular}

As shown in Table 4, while mucking the ore, a diesel loader entering a production stope requires $10.2 \mathrm{~m} 3 / \mathrm{s}$ of air, but a rock support drill rig entering later in the cycle requires only $3.6 \mathrm{~m} 3 / \mathrm{s}$ of air. It was assumed that after a blasting operation, $1 \mathrm{~h}$ would be needed to remove the dust and noxious gases from the stope and the auxiliary fan would run at full speed during the reentry time. The total 
airflow requirement was calculated for each production stage as a function of vehicles entering the stope.

A production cycle consists of drilling, explosive charging, blasting the ore, mucking, cleaning, and rock support operations. In the model study, it was assumed that a production cycle would be completed in $12 \mathrm{~h}$ (Table 5). For each operating period, the total energy consumption of VSD-installed fan motors was calculated on the basis of the data obtained from Figure 5. After blasting the ore, it was assumed that the reentry time would be $1 \mathrm{~h}$, and during this period, the fan motors would run at full speed to remove toxic and noxious gases from the environment.

It was assumed that the fan would operate for $24 \mathrm{~h}$ per day and 340 days per year $(8,160 \mathrm{~h})$ without VSD. Without VSD control and at an energy cost of $\$ 0.10 / \mathrm{kWh}$, the annual electricity cost of the fan (AECFAN) will be

$\operatorname{AECFAN~}=(75 \mathrm{~kW}) \times(8,160 \mathrm{~h}) \times(\$ 0.10 / \mathrm{kWh})=\$ 61,200 /$ year

It can be seen from Table 5 that by using a VSD-installed fan, the total energy consumption is $423.08 \mathrm{~kW}$ per 12 -h mining cycle and the daily consumption is $846.16 \mathrm{~kW}$. On a 340-days-per-year working base, the annual consumption will be $287,695 \mathrm{~kW}$. With a VSD installation and an energy cost of $\$ 0.10 / \mathrm{kWh}$, the annual electricity cost of the fan (AECVSD) will be

$$
\operatorname{AECVSD}=(287,695 \mathrm{~kW}) \times(\$ 0.10 / \mathrm{kWh})=\$ 28,770 / \text { year }
$$

\begin{tabular}{|c|c|c|c|c|c|}
\hline \multirow[t]{2}{*}{ Operation } & \multirow[t]{2}{*}{ Duration (h) } & \multicolumn{2}{|c|}{$\begin{array}{c}\text { Airflow } \\
\text { requirement }\end{array}$} & \multicolumn{2}{|c|}{ Energy consumption } \\
\hline & & $\left(\mathrm{m}^{3} / \mathrm{s}\right)$ & $(\%)$ & (kWh) & (Total kW) \\
\hline Drilling & 4 & 18.60 & 68.89 & 28.59 & 114.36 \\
\hline Explosive charging & 2 & 17.70 & 65.56 & 25.10 & 50.20 \\
\hline $\begin{array}{l}\text { Blasting } \\
\text { reentry }\end{array}$ & 1 & 27.00 & 100.0 & 75.00 & 75.00 \\
\hline Mucking & 3 & 23.40 & 86.67 & 52.22 & 156.66 \\
\hline $\begin{array}{l}\text { Cleaning and rock } \\
\text { support }\end{array}$ & 2 & 13.80 & 51.11 & 13.43 & 26.86 \\
\hline Total (cycle) & 12 & & & & 423.08 \\
\hline
\end{tabular}

Therefore, the annual energy cost saving (AECS) will be

$$
\begin{aligned}
& \text { AECS }=\text { AECFAN }- \text { AECVSD } \\
& \text { AECS }=\$ 61,200 / \text { year }-\$ 28,770 / \text { year }=\$ 32,430 / \text { year }
\end{aligned}
$$

As can be seen from the results, by installing a VSD in an auxiliary ventilation system, as much as $53 \%$ of energy could be saved. 


\subsection{PAYBACK PERIOD OF THE SYSTEM}

The payback period of a VSD (PBPVSD) is a function of the incremental cost of the VSD (ICVSD) divided by the AECS in a particular year. The simple payback period can be expressed as follows:

$$
P B P_{V S D}=\frac{I C_{V S D}}{A E C S}
$$

The cost of VSD per kilowatt decreases with increase in the power rating. Low-voltage VSD total costs of about US $\$ 200 / \mathrm{kW}$ for a $75-\mathrm{kW}$ unit and US $\$ 117 / \mathrm{kW}$ for a 275-kW unit were reported in South Africa during 2013 (Teitel et al. (2008)). The total cost includes the VSD costs and the costs associated with consultation, cabling, installation, and commissioning. Therefore, for a 75-kW auxiliary ventilation fan, the total implementation cost of a VSD is assumed to be $\$ 15,000$. Calculations of energy savings showed that a simple payback could be achieved in 5 months 220 days.

\subsection{ENVIRONMENTAL EFFECT}

The application of VOD technology benefits the environment through reductions in energy consumption, which helps to reduce the environmental impact of greenhouse gas emissions. The $\mathrm{CO} 2$ emission for electricity generated in Turkey was $0.48 \mathrm{~kg} / \mathrm{kWh}(\mathrm{ABB}, 2012)$. The estimated energy savings based on the proposed VOD configuration in the auxiliary ventilation system is $324,300 \mathrm{~kW}$, equivalent to a reduction of 155.6 tons of $\mathrm{CO} 2$ per year.

\section{RESULTS}

In this paper, the energy-saving possibilities when using a VSD in a mine auxiliary fan have been investigated. It was assumed that without any control unit, a 75-kW auxiliary ventilation fan runs continuously at full speed for 340 days per year. In any case, during a lot of that time, the motor does not need to work at maximum speed. By installing a VSD control, the motor will be allowed to operate on an event-based schedule. In a production cycle, the airflow requirement changes with different operations in the stope. The energy savings are due to the decreased power requirement for the operation of motors at reduced speeds. A $53 \%$ reduction in the energy consumption of the fan is possible by adjusting the fan speed with a VSD unit. This means that $324,300 \mathrm{kWh}$ of electrical energy can be saved in a year, and CO2 emissions can be reduced by 155.6 tons per year. Furthermore, the VSD payback period can be achieved in just 5 months 220 days.

\section{DISCUSSION}

The system recommended in this study involves event-based ventilation control; it can reduce operating costs because of the significant reductions in the power supplied to auxiliary fans. More efficient ventilation system can increase the production rate in mines because the ore can be simultaneously extracted from multiple production stopes. Considering the number of stopes that need to be 
ventilated by a permanently installed auxiliary fan, it is possible to save a significant amount of energy for the entire mine. These savings can be increased further when the maintenance issues because of lower fan speeds are reduced. The rise in VSD popularity has led to significant cost reductions in recent years. As the cost of electric power continues to increase, VSDs are becoming even more popular. Payback on a VSD is usually less than 2 years and could be as little as 3 months. The financial viability of installing a VSD depends on the cost of electricity, fan size, length of running time, and desired reduction in the airflow rate. Optimized mine ventilation systems are expected to provide total energy savings and achieve safety, energy efficiency, and a smaller environmental footprint in mines.

\section{REFERENCES}

Dubey, G.K. (2001) Fundamentals of Electrical Drives, 2nd ed. Alpha Science International Ltd. Pangbourne, United Kingdom. Pp. 679.

E.I.O. (2019) U.S. Energy Information Administration, International Energy Outlook. Available Online: Retrieved from https://www.eia.gov/outlooks/ieo/pdf/ieo2019.pdf (last accessed on 13.07.2020).

Gonen. (2018) Implementation of Variable Frequency Drive on Underground Main Fans for Energy Savings-Case Study. International Journal of Modern Research in Engineering and Technology Volume 3 Issue 1, p 31-36.

Halim, A. (2017) Ventilation Requirements for Diesel Equipment in Underground Mines - Are We Using The Correct Values. Proceedings of the 16th North American Mine Ventilation Symposium. Colorado School of Mines. Colorado, USA.

I.E.A. (2019) Global Energy \& CO2 Status Report. Available Online: Retrieved from https://www.iea.org/reports/global-energy-co2-status-report2019/emissions (last accessed on 13.07.2020).

Kaya, D. \& Kilic, F. (2004) Energy Conservation Opportunity İn VSD System-A Case Study. Proceedings of the 27th World Energy Engineering Congress. The Association of Energy Engineers. Atlanta, USA.

Khalid, N. (2014) Efficient energy management: Is variable frequency drives the solution. Procedia Social and Behavioral Sciences, 145: 371-376. Retrieved from https://doi.org/10.1016/j.sbspro.2014.06.046

Lönnberg, M. (2007) Variable speed drives for energy savings in hospitals. World Pumps, 494: 20-24. Retrieved from https://doi.org/10.1016/S02621762(07)70395-4

Malli, T. \& Yetkin, M.E. (2019) An optimization approach for panel dimension design in underground coal mines. Kuwait Journal of Science, 46 (1): 90-98.

McPherson, M.J. (1993) Subsurface Ventilation Engineering, 2nd ed. Chapman \& Hall. London, United Kingdom. Pp. 520. Retrieved from https://doi.org/10.1007/978-94-011-1550-6_4

Mecrow, B.C. \& Jack, A.G. (2008) Efficiency trends in electric machines and drives. Energy Policy, 36(12): 4336-4341. Retrieved from https://doi.org/10.1016/j.enpol.2008.09.042 
Ozdemir, E. (2004) Energy conservation opportunities with a variable speed controller in a boiler house. Applied Thermal Engineering, 24(7): 981-993. Retrieved from https://doi.org/10.1016/j.applthermaleng.2003.11.009

Plessis, G.E., Liebenberg, L. \& Mathews E.H. (2013) The use of variable speed drives for cost-effective energy savings in South African mine cooling systems. Applied Energy, 111: 16-27. Retrieved from https://doi.org/10.1016/j.apenergy.2013.04.061

Saidur, R., Rahim, N.A. \& Hasanuzzaman, M. (2010) A review on compressed-air energy use and energy savings. Renewable and Sustainable Energy Reviews, 14(4): 1135-1153. $\quad$ Retrieved from https://doi.org/10.1016/j.rser.2009.11.013

Simpson, A.R. \& Marchi A. (2013) Evaluating the approximation of the affinity laws and improving the efficiency estimate for variable speed pumps. Journal of Hydraulic Engineering, 139(12): 1314-1317. Retrieved from https://doi.org/10.1061/(ASCE)HY.1943-7900.0000776

Stephan, G. (2011) Cut-and-fill mining. In: Darling, P. (Ed.). SME Mining Engineering Handbook, Pp. 1365-1373. Society for Mining Metallurgy and Exploration Inc., Colorado, USA.

Teitel, M., Levi, A., Zhao, Y., Barak, M., Barlev, E. \& Shmuel, D. (2008) Energy saving in agricultural buildings through fan motor control by variable frequency drives. Energy and Buildings, 40(6): 953-960. Retrieved from https://doi.org/10.1016/j.enbuild.2007.07.010

Tolvanen, J. (2008) Saving energy with variable speed drives. World Pumps, 501: 32-33. Retrieved from https://doi.org/10.1016/S0262-1762(08)70164-0

Tuck, M.A. (2011) Mine ventilation. In: Darling, P. (Ed.). SME Mining Engineering Handbook, Pp. 1577-1594. Society for Mining Metallurgy and Exploration Inc., Colorado, USA.

Wallace, K., Prosser, B. \& Stinnette, J.D. (2015) The practice of mine ventilation engineering. International Journal of Mining Science and Technology, 25: 165-169. Retrieved from https://doi.org/10.1016/j.ijmst.2015.02.001 